\title{
Contrasting patterns of coronary atherosclerosis in normocholesterolaemic smokers and patients with familial hypercholesterolaemia
}

\author{
D D SUGRUE, G R THOMPSON, C M OAKLEY, I M TRAYNER, R E STEINER
}

\begin{abstract}
An angiographic comparison was made of the extent and severity of coronary artery disease in 25 patients with heterozygous familial hypercholesterolaemia and 25 normocholesterolaemic patients with coronary artery disease in whom heavy cigarette consumption was the chief risk factor. The patients with familial hypercholesterolaemia were younger and included a much higher proportion of women than the smokers.

Significantly more patients with familial hypercholesterolaemia had disease of the main stem of the left coronary artery (eight $v$ none, $p<0.05$ ) and triple-vessel disease (18 $v$ four, $p<0.05)$. Disease affecting only distal vessels occurred in five smokers, whereas all the patients with familial hypercholesterolaemia showed a combination of proximal and distal lesions.

These findings suggest that cigarette smoking and familial hypercholesterolaemia predispose to different patterns of coronary atheroma. Early coronary angiography with a view to coronary artery bypass surgery seems desirable in symptomatic patients with familial hypercholesterolaemia because of the common association of this disorder with life-threatening left mainstem disease.
\end{abstract}

\section{Introduction}

The risk of premature coronary artery disease is greatly increased in both men and women with heterozygous familial hypercholesterolaemia (familial type II hyperlipoproteinaemia).$^{1-3}$ Bloch et al ${ }^{4}$ reported a distinctive angiographic pattern of coronary atheroma in a fairly heterogeneous group of patients with type II hyperlipoproteinaemia, which included three homozygotes for familial hypercholesterolaemia, compared with patients with type IV hyperlipoproteinaemia. ${ }^{4} \mathrm{We}$ report here a comparison of coronary angiographic findings in 25 patients with heterozygous familial hypercholesterolaemia and 25 cigarette smokers with normal cholesterol concentrations.

\section{Patients and methods}

Twenty-five patients with heterozygous familial hypercholesterolaemia - that is, serum cholesterol concentration $>6.5 \mathrm{mmol} / 1(>250$ $\mathrm{mg} / 100 \mathrm{ml}$ ) together with tendon xanthomas or the presence of hypercholesteraemia in a first-degree relative-underwent left ventriculography and selective coronary angiography during the period 1968-80. Records were reviewed of patients without hyper-

\footnotetext{
Departments of Clinical Cardiology, Chemical Pathology, and Diagnostic Radiology, Royal Postgraduate Medical School, and MRC Lipid Metabolism Unit, Hammersmith Hospital, London W12 OHS

D D SUGRUE, MB, MRCP, research fellow in cardiology

G R THOMPSON, MD, FRCP, consultant physician

C M OAKLEY, MD, FRCP, consultant physician

I M TRAYNER, $\mathrm{MB}, \mathrm{BCH}$, registrar in chemical pathology

R E STEINER, MD, FRCR, professor of diagnostic radiology
}

cholesterolaemia who had undergone angiography during this period and the angiograms of 25 in whom current heavy cigarette consumption ( $>20 /$ day) was the only chief risk factor analysed. Angina pectoris was the indication for angiography in every instance in both groups of patients. Fasting serum cholesterol concentration was measured on a sequential multiple analyser ${ }^{5}$ in the smokers and by an enzymatic method ${ }^{6}$ in the patients with familial hypercholesterolaemia. Serum triglyceride and high-density-lipoprotein (HDL) cholesterol ${ }^{7}$ concentrations were measured in only the patients with familial disease, and the HDL ratio was calculated as HDL cholesterol to total minus HDL cholesterol. ${ }^{7}$ Table I gives clinical details of the two groups of patients.

Cardiac catheterisation was performed using the Judkins technique. ${ }^{8}$ Coronary arteriograms were obtained in standard multiple projections and ventriculography performed in the right anterior oblique projection. Arteriograms were reviewed by one of us (RES) without prior knowledge of patient category. The coronary arterial system was arbitrarily divided into "proximal" and "distal" territories. The proximal territory extended as far as the right atrial branch of the right coronary artery, the second diagonal branch of the left anterior descending artery, and the second obtuse marginal branch of the circumflex coronary artery. Vessels beyond these demarcation points were regarded as distal. Lesions that caused a $50 \%$ or greater reduction in luminal diameter when seen in two projections were regarded as important. Ventriculograms were analysed for the presence or absence of dyskinesia. Statistical analysis of angiographic results was performed using the $x^{2}$ test.

\section{Results}

Total serum cholesterol concentration was almost twice as high in the patients with familial hypercholesterolaemia as in the normocholesterolaemic smokers (table I). Further analyses, in only the

TABLE I-Clinical details of patients with familial hypercholesterolaemia and smokers with normal cholesterol concentrations (means $+S D$ )

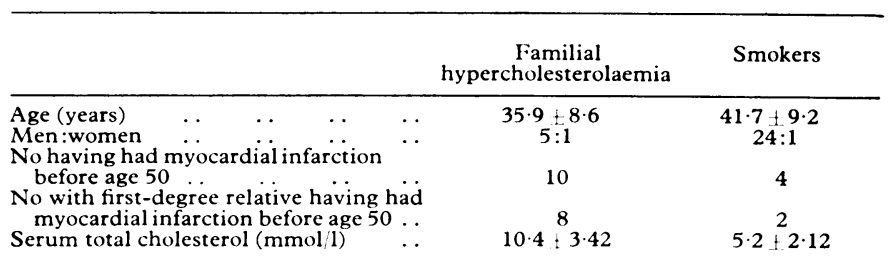

Conversi

patients with familial disease, showed the following mean values: serum triglyceride concentration $2.14 \mathrm{mmol} / 1(189 \mathrm{mg} / 100 \mathrm{ml})$, HDL cholesterol concentration $1.07 \mathrm{mmol} / 1(41 \mathrm{mg} / 100 \mathrm{ml})$, and HDL ratio $0 \cdot 115$; the lipoprotein phenotype ${ }^{9}$ was type IIa in 19 patients and type IIb in six. Compared with the smokers the group with familial hypercholesterolaemia contained more women, more patients with previous myocardial infarction, and more patients with a firstdegree relative with a history of myocardial infarction before the age of 50 . Four of the patients with familial disease had hypertension and three smoked cigarettes. One of the smokers with normal cholesterol concentrations had hypertension.

Table II shows the distribution of appreciable coronary artery lesions. Eight of the 25 patients with familial disease but none of the smokers had strictures of the left main stem $(p<0.05)$. A significantly greater number of patients with familial disease had three-vessel disease with or without accompanying left main-stem disease (18 $v 4$, 
$\mathrm{p}<0.05$ ) (table III). Five of the smokers had disease confined to the distal coronary system, whereas all the patients with familial disease had combined proximal and distal disease $(p>0.05)$. Four of the patients with familial disease had ectasia of the right coronary artery compared with one smoker $(p>0.05)$. Localised ventricular dyskinesia was present in 18 patients with familial disease and 15 smokers $(\mathrm{p}>0.05)$. Within the group with familial disease there were no significant correlations between the presence of left main-stem disease and the severity of hypercholesterolaemia, presence of hypertriglyceridaemia, or decrease in the HDL ratio. vascular coagulation ${ }^{28}$ have also been reported in familial hypercholesterolaemia. A direct comparison of the effects of smoking and hypercholesterolaemia on platelet function and coagulation factors has not been made, however, and these two risk factors might affect haemostatic variables differently, thereby influencing the distribution of atherosclerotic lesions within and between particular vascular territories. The differences in the distributions of age and sex between the two groups of patients were not unexpected, given the enhanced risk of coronary heart

TABLE II-Distribution of coronary artery lesions in 25 patients with heterozygous familial hypercholesterolaemia and 25 smokers. (Figures are numbers (\%) of patients)

\begin{tabular}{|c|c|c|c|c|c|c|}
\hline \multirow[b]{2}{*}{ Coronary artery } & \multicolumn{2}{|c|}{ Complete occlusion } & \multicolumn{2}{|c|}{ Stricture $>50^{\prime \prime}$} & \multicolumn{2}{|c|}{ Ectasia } \\
\hline & $\begin{array}{c}\text { Familial } \\
\text { hyperchol- } \\
\text { esterolaemia }\end{array}$ & Smokers & $\begin{array}{c}\text { Familial } \\
\text { hyperchol- } \\
\text { esterolaemia }\end{array}$ & Smokers & $\begin{array}{c}\text { Familial } \\
\text { hyperchol- } \\
\text { esterolaemia }\end{array}$ & Smokers \\
\hline $\begin{array}{lll}\text { Left main } & \ldots & \ldots \\
\text { Left anterior descending } \\
\text { Circumflex } & \ldots & \ldots \\
\text { Right } \quad \ldots & \ldots & \ldots\end{array}$ & $\begin{array}{l}6(24) \\
2(8) \\
5(20)\end{array}$ & $\begin{array}{l}2(8) \\
1(4) \\
3(12)\end{array}$ & $\begin{array}{l}8(32)^{*} \\
13(52) \\
11(44) \\
12(48)\end{array}$ & $\begin{array}{r}8(32) \\
4(16) \\
11(44)\end{array}$ & $4(16)$ & $1(4)$ \\
\hline
\end{tabular}

${ }^{*} p<0.05$ between the two groups of patients.

TABLE III-Number of diseased vessels and site of lesions in patients with familial hypercholesterolaemia and smokers. (Figures are numbers $(\%)$ of patients)

\begin{tabular}{|c|c|c|c|c|c|c|}
\hline \multirow{2}{*}{$\begin{array}{c}\text { No of } \\
\text { vessels } \\
\text { diseased }\end{array}$} & \multicolumn{3}{|c|}{ Familial hypercholesterolaemia } & \multicolumn{3}{|c|}{ Smokers } \\
\hline & $\begin{array}{c}\text { Proximal } \\
\text { and } \\
\text { distal }\end{array}$ & Distal & Total & $\begin{array}{l}\text { Proximal } \\
\text { and } \\
\text { distal }\end{array}$ & Distal & Total \\
\hline $\begin{array}{l}1 \\
2\end{array}$ & $\begin{array}{l}2 \\
5\end{array}$ & & $2(8)$ & $\begin{array}{r}8 \\
11\end{array}$ & 2 & $\begin{array}{r}8(32) \\
13(52)\end{array}$ \\
\hline $\begin{array}{l}3 \\
4+\end{array}$ & $\begin{array}{r}10 \\
8\end{array}$ & & $\left.\begin{array}{r}10 \\
8\end{array}\right\} 18(72)^{*}$ & 1 & 3 & $4\} 4(16)$ \\
\hline Total & 25 & & 25 & 20 & 5 & 25 \\
\hline
\end{tabular}

* $p<0.05$ between the two groups.

+ Three vessels plus left main artery.

\section{Discussion}

Numerous angiographic studies have shown an association between hyperlipidaemia and the presence of coronary artery disease. ${ }^{10-14}$ A correlation between the degree of hyperlipidaemia and the severity of coronary lesions, based on various angiographic scoring systems, has also been established. ${ }^{15-17}$ Patients with heterozygous familial hypercholesterolaemia are especially at risk for premature and severe coronary artery disease, with up to $60 \%$ of men and over $30 \%$ of women with the disease developing angina or sustaining a myocardial infarct by the age of $50 .^{11819}$ Cigarette smoking also increases the risk of premature coronary artery disease in both patients with familial hypercholesterolaemia ${ }^{19}$ and the population at large, with an associated doubling of mortality from coronary disease. ${ }^{20}{ }^{21}$ Epidemiological studies have shown that the risk of symptomatic atherosclerosis in cerebral, coronary, and peripheral circulations is affected differently by specific risk factors. Hypertension is the most powerful predictor of cerebrovascular disease, while smoking and increased serum cholesterol concentrations are more closely related to coronary heart disease. ${ }^{22}$

The precise role of thrombogenic mechanisms in the pathogenesis of atherosclerosis has not yet been fully defined. Decreases in platelet survival ${ }^{23}{ }^{24}$ and fibrinolytic activity and increased serum fibrinogen concentrations ${ }^{25}$ occur in smokers and may lead to accelerated intravascular coagulation and thrombosis. An exaggerated platelet response to aggregating agents, ${ }^{26} 27$ raised fibrinogen and factor VIII concentrations (Sugrue $e t$ al, unpublished observations), and accelerated intra- disease in patients with familial hypercholesterolaemia compared with subjects with normal cholesterol concentrations, but there is no evidence that these factors were responsible for the contrasting distribution of lesions between the two groups.

Since this study was retrospective we could not obtain complete lipid data on the group of smokers with coronary heart disease. Previous reports, however, suggest that smokers have an increased incidence of hypertriglyceridaemia ${ }^{29}$ and decreased HDL cholesterol concentrations ${ }^{30}{ }^{31}$ compared with nonsmokers. In these respects smokers resemble type IV patients, such as those studied by Bloch et al, ${ }^{4}$ in whom hypertriglyceridaemia is often accompanied by decreased concentrations of HDL cholesterol and a reduced HDL ratio. A reduced HDL ratio is also a feature of familial hypercholesterolaemia.

Left main-stem disease carries a high early mortality, ${ }^{22}$ but the prognosis is improved by coronary artery bypass surgery. ${ }^{32}{ }^{33}$ The prevalence of left main-stem disease among the patients with familial hypercholesterolaemia in the present series suggests that the presence of angina or an abnormal exercise test is an indication for urgent coronary angiography. In contrast, this lesion is a fairly rare cause of angina in general; a prevalence of around 5\% was found recently in over 1000 people who underwent angiography before the age of $45 .^{34}$

The mechanism of the apparent predilection of atheroma for the proximal portions of the aorta and coronary arteries in homozygotes for familial hypercholesterolaemia has been discussed briefly elsewhere. ${ }^{35}$ Atheroma of the ascending aorta is much less pronounced in heterozygotes, ${ }^{36}$ which presumably reflects their having a less extreme degree of hypercholesterolaemia. A similar proximal distribution of atheromatous lesions is seen in rats with experimentally induced hypercholesterolaemia $^{37}$ corresponding to the areas of maximal shear stress. ${ }^{38}$ Thus superimposition of increased plasma low-density lipoprotein concentrations on a normal haemodynamic background appears to result in an unusually proximal distribution of atherosclerosis, the severity of the hypercholesterolaemia apparently determining whether the lesions affect the aortic valve and coronary ostia, as in homozygotes, ${ }^{35}$ or the proximal parts of the main coronary arteries themselves, as in the heterozygotes in this study. The pathogenesis of the more distal lesions in the smokers remains uncertain, but the differences observed between the two groups of patients suggest that differing mechanisms played a part.

DDS was supported by a grant from Heart. 


\section{References}

1 Slack J. Risks of ischaemic heart disease in familial hyperlipoproteinaemic states. Lancet 1969;ii:1380-2.

${ }^{2}$ Stone JJ, Levy RI, Fredrickson RI, Verter J. Coronary artery disease in 116 kindred with familial type II hyperlipoproteinaemia. Circulation $1974 ; 49: 476-88$

${ }^{3}$ Mabuchi H, Ito S, Haba $\mathrm{T}$, et al. Discrimination of familial hypercholesterolaemia and secondary hypercholesterolaemia by Achilles tendon thickness. Atherosclerosis 1977;28:61-8.

${ }^{4}$ Bloch A, Dinsmore RE, Lees RS. Coronary arteriographic findings in type II and type IV hyperlipoproteinaemia. Lancet 1976;i:928-30.

${ }^{5}$ Huang TC, Chen CP, Wefler V, Raftery A. A stable reagent for the Liebermann-Burchard reaction. Application to rapid serum cholesterol determination. Anal Chem 1961;32:1405-7.

${ }^{6}$ Anonymous. Manual of laboratory operations, lipid research clinics program. Vol 1. Lipids and lipoprotein analysis. DHEW Publications No (NIH) 75-628. Washington: DHEW, 1974.

${ }^{7}$ Mjos OD, Thelle DS, Forde OH. Familial study of high density lipoprotein cholesterol and relation to age and sex. The Tromso heart study. Acta Med Scand 1977;201:323-9.

${ }^{8}$ Judkins MP. Selective coronary radiography. A percutaneous approach. Radiology 1967;89:815-24.

${ }^{9}$ Beaumont JL, Carlson LA, Cooper GR, Feijar Z, Fredrickson DS, Strasser J. Classification of hyperlipidaemia and hyperlipoproteinaemia. WHO Bull 1970;43:891-908.

${ }^{10}$ Falsetti HL, Schnatz JD, Green DG, Bunnell IL. Lipid and carbohydrate studies in coronary artery disease. Circulation 1968;37:184-91.

11 Heinle RA, Levy RI, Fredrickson RS, Gorlin R. Lipid and carbohydrate abnormalities in patients with angiographically documented coronary artery disease. Am $\mathcal{F}$ Cardiol 1969;24:178-86.

12 Barboriak JJ, Rimm A, Tristani FE, Walker JR, Lepley D. Risk factors in patients undergoing aorto-coronary bypass surgery. $\mathcal{f}$ Thorac Cardiovasc Surg 1972;64:92-7.

${ }^{13}$ Barboriak JJ, Rimm AA, Anderson AJ, Tristani FE, Walker JR, Hemme RJ. Coronary artery'occlusions and blood lipids. Am Heart f 1974;87 $716-21$.

14 Gotto A, Gorry GA, Thompson JR, et al. Relationship between plasma lipid concentrations and coronary artery disease in 496 patients. Circulation 1977;56:875-83.

${ }^{15}$ Banks DC, Raftery EB, Oram S. Clinical significance of the coronary arteriogram. Br Heart 7 1971;33:863-70.

${ }^{16}$ Nitter-Hauge S, Enge I. Relationship between blood lipid levels and angiographically evaluated obstructions in coronary arteries. $\mathrm{Br} \mathrm{Heart} \mathfrak{f}$ $1973 ; 35: 791-5$

${ }_{17}$ Murray RG, Tweddel A, Third J, Hutton I. Relation between extent of coronary artery disease and severity of hyperlipoproteinaemia. $\mathrm{Br}$ Heart f 1975;37:1205-9.

${ }^{18}$ Heiberg A. The risk of atherosclerotic vascular disease in subjects with xanthomatosis. Acta Med Scand 1975;198:249-61.

${ }^{19}$ Beaumont V, Jacotot B, Beaumont JL. Ischaemic disease in men and women with familial hypercholesterolaemia and xanthomatosis. A comparative study of genetic and environmental factors in 274 heterozygous cases. Atherosclerosis $1976 ; \mathbf{2 4}: 441-50$.

${ }^{20}$ Doyle JT, Dawber JT, Kannel WB, Haslin AS, Kahn HA. Cigarette smoking and coronary heart disease. N Engl f Med 1962;266:796-801.

${ }^{21}$ Reid DD, Hamilton PJS, McCartney P, Rose G, Jarrett RJ, Keen H. Smoking and other risk factors for coronary heart discase in British civil servants. Lancet 1976;ii:979-84.

${ }^{22}$ Gordon T, Kannel WB. Predisposition to atherosclerosis in the head, heart and legs. The Framingham study. $\mathcal{F} A M A$ 1972;22:661-6.

${ }^{23}$ Mustard JF, Murphy EA. Effect of smoking on blood coagulation and platelet survival in man. $\mathrm{Br}$ Med $\mathcal{F} 1963$; : :846-9.

${ }^{24}$ Hawkins RI. Smoking, platelets and thrombosis. Nature 1972;236:450-2.

${ }^{25}$ Meade TW, Charkrabarti R, Haines AP, North WRS, Stirling Y. Characteristics affecting fibrinolytic activity and plasma fibrinogen concentrations. Br Med f 1979;i:153-6.

26 Carvalho AC, Colman RW, Lees RS. Platelet function in hyperlipoproteinaemia. N Engl f Med 1974;290:434-48.

${ }^{27}$ Nordoy A, Rodset JM. Platelet function and platelet phospholipids in patients with hyperbetalipoproteinaemia: effect of nicotinic acid and clofibrate. Acta Med Scand 1971;189:385-9.

${ }_{28}$ Carvalho ACA, Lees RS. Platelets, intravascular coagulation and fibrinolysis in hyperlipidaemia : relationship to thromboembolic complications. Acta Med Scand 1979;suppl 642:101-2.

29 Trayner IM, Mannarino E, Clyne CAC, Thompson GR. Serum lipids and high density lipoprotein cholesterol in peripheral vascular disease. Br f Surg 1980;67:497-9.

${ }^{30}$ Williams P, Robinson D, Bailey A. High density lipoprotein and coronary risk factors in normal men. Lancet $1979 ; \mathrm{i}: 72-5$.

${ }^{31}$ Garrison RJ, Kannel WB, Feineil M, et al. Cigarette smoking and HDL cholesterol. The Framingham study. Atherosclerosis 1979;30:17-25.

32 Lim JS, Proudfit WL, Sones FM Jr. Left main coronary arterial obstruction: longterm follow-up of 141 non-surgical cases. Am $\mathcal{F}$ Cardiol 1975; $36: 131-5$.

${ }^{33}$ Takaro T, Hultgren HN, Lipton MJ. The VA co-operative randomised study of surgery for coronary arterial occlusive disease. II. Subgroup with significant left main lesions. Circulation 1976;54:suppl III : 107-17.

${ }^{34}$ Critten J, Waters DD, Theroux P, Mizgala HF. Left main coronary artery stenosis in young patients. Chest 1979;76:508-13.

${ }^{35}$ Allen JM, Thompson GR, Myant NB, Steiner R, Oakley CM. Cardiovascular complications of homozygous familial hypercholesterolaemia. Br Heart f 1980;44:361-8.

${ }^{36}$ Roberts WC. The status of coronary arteries in fatal ischaemic heart disease. Cardiovasc Clin 1975; 7:1-24.

${ }^{37}$ Zahor Z, Czabanova V. Experimental atherosclerosis of the heart valve in rats following a long-term atherogenic regimen. Atherosclerosis 1977; $27: 49-57$

${ }^{38}$ Fry DL. Responses of the arterial wall to certain physical factors in atherogenesis: initiating factors. Ciba Found Symp 1973;No 12:93-125.

(Accepted 12 August 1981)

\section{SHORT REPORTS}

\section{Treatment of erythema multiforme secondary to herpes simplex by prophylactic topical acyclovir}

Erythema multiforme may occur repeatedly after recurrent herpes simplex lesions. There is considerable morbidity, and treatment is usually unsatisfactory. We report a case of intractable erythema multiforme after recurrent herpes labialis in which there was sustained benefit from prophylactic topical application of acyclovir.

\section{Case report}

A 51-year-old woman began developing erythema multiforme in 1976 coincident with her menopause. Each attack consisted of painful target lesions on the hands, feet, elbows, and knees, usually in association with oral, vaginal, and conjunctival ulceration, and sometimes with headache and general malaise. Attacks began 10 to 14 days after episodes of blistering and crusting around the mouth typical of herpes labialis. On several occasions herpes simplex virus was isolated from these lesions. Initially erythema multiforme occurred every few months, but the frequency and severity increased progressively so that by 1978 she was having erythema multiforme continuously.

Investigations for other possible causes of erythema multiforme were negative. Clq-binding immune complexes were detected at the onset of erythema multiforme but total haemolytic complement, C3, and C4 concentrations were within normal limits. The herpes simplex complement-fixing antibody titre was $1 / 16$ to $1 / 32$. A succession of treatments had little or no effect. Idoxuridine $5 \%$ in dimethylsulphoxide reduced the severity of the herpes labialis but had no effect on the erythema multiforme; prednisolone $30 \mathrm{mg}$ daily partially suppressed the erythema multiforme; and superficial radiotherapy (total dose 300 rads over four weeks) was followed by a remission lasting three months.

In February 1979, within two hours of the onset of herpes labialis, she was treated with intravenous acyclovir (Wellcome) $5 \mathrm{mg} / \mathrm{kg}$ eight-hourly for five days. One week later she suffered a further attack of erythema multiforme and a new outbreak of herpes labialis. In April she began applying $5 \%$ topical acyclovir around the mouth five times daily, but after four weeks this was reduced to twice daily. Subsequently she had only one attack of fully developed erythema multiforme, during a period of one month when she stopped using the cream. During the first 10 months of treatment there were several minor episodes of herpes simplex in the nostrils and uccasional papular lesions of erythema multiforme on the fingers, but in the ensuing 10 months there were no further lesions.

\section{Comment}

A causal relation between erythema multiforme and herpes simplex infection has long been suspected clinically, though the pathogenesis is still not clear. Several studies have indicated that immune complexes 